\title{
Natural science education - a claim for equality, diversity and inclusion in citizen science activities
}

\author{
Neuböck-Hubinger, Brigitte ${ }^{a, *} ;$ Grubner, Katharina $^{a}$; Frigerio, Didone ${ }^{b, c}$ \& \\ Hirschenhauser, Katharina ${ }^{a, *}$
}

a University for Education Upper Austria (PH Ö̈), Kaplanhofstraße 40, 4020 Linz, Austria

E-mail: brigitte.neuboeck-hubinger@ph-ooe.at, katharina.grubner@ph-ooe.at, katharina.hirschenhauser@ph-ooe.at

b Konrad Lorenz Research Center, Core Facility for Behaviour and Cognition, University of Vienna, Fischerau 11, 4645 Grünau, Austria

E-mail: didone.frigerio@univie.ac.at

c Department for Behavioural and Cognitive Biology, University of Vienna,

Althanstrasse 14, 1090 Vienna, Austria

E-mail: didone.frigerio@univie.ac.at

Citizen science projects with a focus on involving educational institutions aim at the participation of pupils and teachers in scientific research. In the present study, we scrutinized the cultural and inclusive quality of the funded projects "Sparkling Science" by examining whether aspects of inclusion were taken into account in the various projects with focus on natural science topics $(N=33)$, funded by the program in the frame of two calls for proposals (i.e. 5th call 2012 - 2015 and 6th call 2017 - 2019). This article is intended to stimulate discussion on how to take up the central idea of inclusion (also) in the sense of a democratization of science.

Vienna - Austria

* Speaker

(C) Copyright owned by the author(s) under the terms of the Creative Commons

Attribution-NonCommercial-NoDerivatives 4.0 International License (CC BY-NC-ND 4.0). 


\section{Introduction}

Citizen science projects with a focus on involving educational institutions aim at the participation of pupils and teachers in scientific research. From the educational perspective, these activities may enable the scientific literacy of students and ultimately, alter the general attitude towards research in society [1]. Scientific literacy is worthwhile for society and the national account systems, as individuals and communities may benefit economically and socially. This contributes to promote active citizenship and enables people to participate in, and shape technological and scientific developments in society [2]. Citizen science activities may therefore contribute to the democratization of society [3]. With respect to the volunteer and democratic nature of project participations, considering aspects of equality, diversity, and inclusion (EDI, e.g. [4]) is essential for generating and fostering a culture of inclusive attitudes. Inclusion refers to the heterogeneity of society and requires the comprehensive participation of all people in social and professional life [5], including formal education at school and extracurricular learning opportunities. Furthermore, by ratifying the UN Convention on the Rights of Persons with Disabilities in 2008, Austria has committed to meeting the demands for inclusion at all levels of society (BGBI. III Nr. 155/2008). We present evidence that aspects of EDI are not yet routine in extracurricular educational science programs [1], especially in the field of the natural sciences. Furthermore, the studied projects took place in an aera of high levels of cultural heterogeneity (due to the European refugee crisis) and schools had to deal with children who suffered from language barriers and/or socio-emotional problems due to migratory experiences. Children generally show great interest and curiosity to explore their environment [6]. Children's interest is particularly focused on nature, living objects and scientific topics. According to biophilia [7], this is adaptive and part of human universals as the health and well-being of people are closely linked to natural environments. Therefore, the lack of sensibility for EDI demands in natural science activities is regarded a dropped chance and also beyond the national scope, raising sensibility for EDI is relevant for citizen science approaches.

\section{Materials and methodology}

We conducted a survey on the consideration of EDI aspects in extracurricular educational science projects within a specific funding program. From 2007 to 2017 the Austrian Federal Ministry for Science, Research and Education promoted the funding program "Sparkling Science" to foster the collaboration between science and education by actively involving school pupils in scientific research projects [8,9]. In the present study, we scrutinized the cultural and inclusive quality of the funded projects by examining whether aspects of inclusion were taken into account in the various projects funded by the program in the frame of two calls for proposals (i.e. 5 th call 2012 - 2015 and 6th call 2017 - 2019).

A total number of 81 projects from various fields were granted in the frame of the 5th and 6th calls and of these, 33 projects had a focus on natural science topics [8 and 9]. By means of document analysis of the published project summaries, we systematically reviewed qualitative text measures, which were assumed to be good indicators for the application of EDI. The texts of the 33 project summaries were scanned for termini indicative of EDI aspects, such as inclusion, 
diversity, interculturality, social and cultural heterogeneity.

As a data frame, three exemplary cases of disadvantaged participation were envisioned. These cases included the consideration of physical handicaps, language barriers, and socioemotional problems.

\section{Results}

In the studied sample, most participants were from secondary school classes (i. e. pupils aged 10 to 14 years, or students 15 to 18 -years old). Most participating schools were secondary level with 9th to 12th grade students. Fewer primary schools and secondary schools with 5th to 8th grade levels (so-called "Mittelschulen"), which represent the sample of pupils in compulsory education (i. e. pupils aged between 6 and 14 years) participated in the Sparkling Science projects. Thus, younger children were underrepresented in the sample (Fig. 1). One project was outstanding with regard to EDI - the participating school was a school for deaf children. Especially because this deliberately chosen cooperation required a lot of individual differentiation and new ways of collaboration from the beginning on.

$$
5^{\text {th }} \text { call }
$$

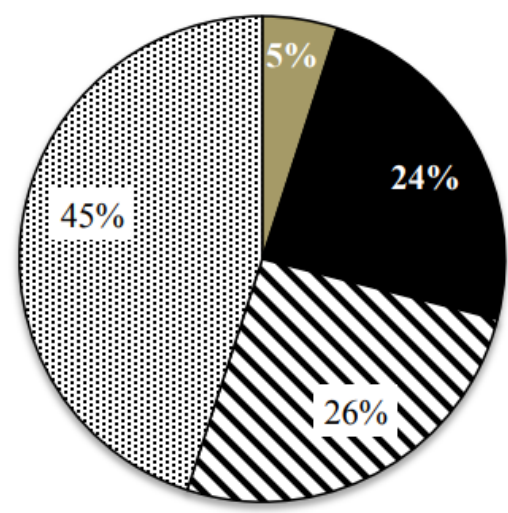

$6^{\text {th }}$ call

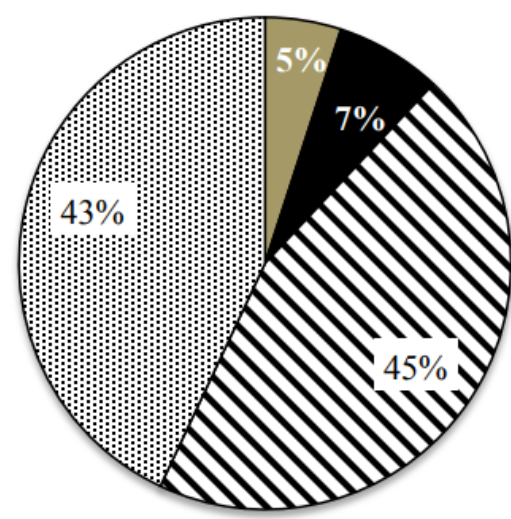

Fig. 1: Age structure of the sample and school types involved in the studied Sparkling science projects; numbers are percentages of all science education projects that were funded per call $\left(5^{\text {th }}\right.$ call: $N=20 ; 6^{\text {th }}$ call: $N=13$ )

Among the 33 projects in the field of natural sciences, only $27 \%$ of the summaries of funded projects exhibited some consideration of EDI aspects. Thus, $73 \%$ of the funded projects did not deal with any inclusive aspects of education (Fig. 2). Thus, in the studied sample, a significant lack of text measures that would indicate the inclusion of disadvantaged students was observed. 


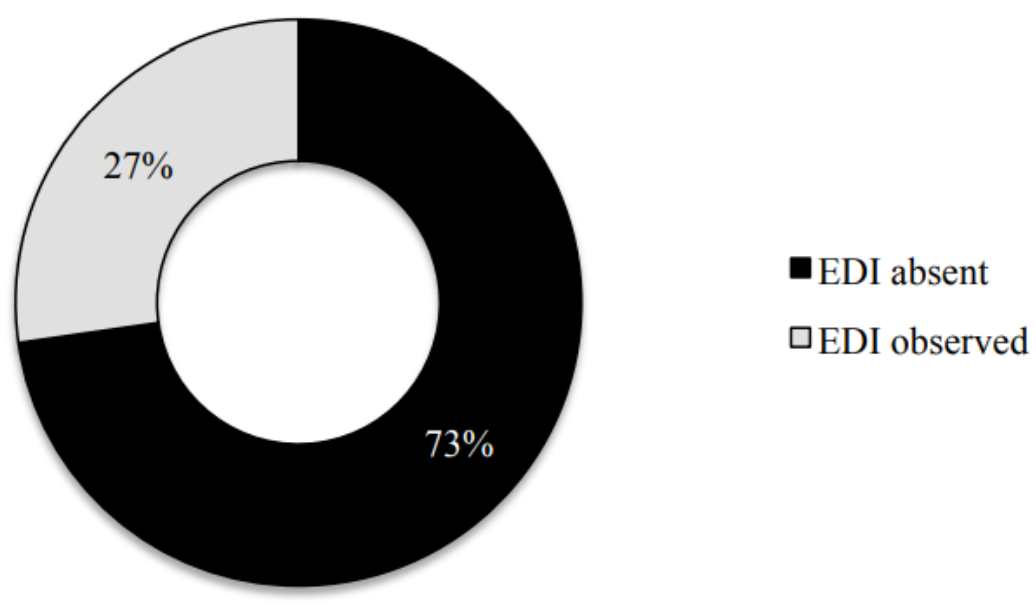

Fig. 2: Proportions of EDI text measures in the published summaries of all funded science education projects, $5^{\text {th }}$ and $6^{\text {th }}$ call $(N=33)$.

\section{Discussion}

Further research on the personal views and project-specific experiences of the involved scientists and teachers may provide more detailed information on the practice of scienceeducation collaborations. However, criteria for funding obviously did not include the consideration of EDI aspects to compensate for disadvantaged participation. Therefore, we consider this result as indicator for a current routine of extracurricular activities in (natural) science education. This is anachronistic in the light of the UN Convention on the Rights of Persons with Disabilities going back to 2008. It points at the mandatory need to raise more sensibility for EDI in science education, which includes scientists involving schools in their research (such as education-based citizen science), as well as funding agencies that are promoting the collaboration between science and education.

Schools are obliged to implement EDI aspects by law. It is therefore even more important to include all pupils into extracurricular science projects - even if barriers may be challenging. Especially citizen science projects could be a chance for disadvantaged children to be noticed and appreciated, as well as to expand their knowledge and impressions. The cooperation between science and education is valuable also in the perspectives of citizen science [1]; however, in the field of natural sciences it suffers from the lack of awareness for EDI. We resume that awareness raising is needed at the side of scientists, as the reviewed project summaries were written by the scientists. Moreover, the results of this survey suggest claiming for action at the side of funding agencies, as the criteria for project funding did not demand the consideration of EDI. At least, these criteria were not made public and were not clearly stated in the application guidelines. As soon as schools are involved in any citizen science activities, consideration of EDI is obligatory for teachers $[4,8]$ and thus, for all players involved - including scientists.

Citizen science is a yet raising scientific domain and should be ready to pick up responsibility for developing inclusive practices and cultures. In addition, funding agencies have 
a potential governance role to implement and realize awareness for EDI in extracurricular educational science projects, e. g. by providing incentives for the attention to EDI in extracurricular education projects. For example, in the last generation of the studied funding program (2017 - 2019), the specific advancement of activating girls' interests in technical disciplines was encouraged with a supplementary budget. This incentive effectively changed the project proposers' initiatives to specifically involve girls in research activities in the fields of natural sciences [9]. Similar pull factors, as well as best practice examples, may well be effective in fostering the awareness for the need to consider EDI in future citizen science calls. Citizen Science is an innovative method. Why doesn't it follow contemporary societal tasks and claims also in natural science education? Probably, small adaptations may be sufficient to compensate for disadvantages and enable the participation of all individuals. Therefore, we propose to regard this report as a claim for raising the sensibility of proposers for EDI in citizen science activities.

\section{References}

[1] D. Frigerio, P. Pipek, S. Kimmig, J. Melzheimer, L. Diblikova, B. Wachter \& A. Richter, Citizen science and wildlife biology: Synergies and challenges. Ethology 124 (6), 365-377, 2018 [doi.org/10.1111/eth.12746].

[2] L. Archer, E. Dawson, A. Seakins, B. Wong, Disorientating, fun or meaningful? Disadvantaged families' experiences of a science museum visit. Cultural Studies of Science Education 11 (4), 917-939, 2006 [doi.org/10.1007/s11422-015-9667-7].

[3] H. Collins, Can we teach people what science is really like? Science Education 99 (6), 10491054, 2015 [doi.org/10.1002/sce.21189].

[4] A. Textor, Einführung in die Inklusionspädagogik, Julius Klinkhardt 2015.

[5] A. Booth, M. Ainscow, Index for Inclusion, CSIE, Bristol 2002 [http://www.eenet.org.uk/resources/docs/Index\%20English.pdf].

[6] S. Koerber, Entwicklung des wissenschaftlichen Denkens bei Vier- bis Achtjährigen. Beiträge zur Lehrerinnen- und Lehrerbildung 24 (2), 192-201, 2006.

[7] S. R. Kellert \& E. O. Wilson, The biophilia hypothesis, Island Press 1995.

[8] BMWF (Bundesministerium für Wissenschaft und Forschung), Sparkling Science Wissenschaft ruft Schule. Schule ruft Wissenschaft, Programmheft 2013 [https://www.sparklingscience.at/ Resources/Persistent/829c037d33fddb3dfca5ac515997a2a929f81bad/Forschungsprojekte_Stand_Juni_2013.pdf].

[9] BMBWF (Bundesministerium für Bildung, Wissenschaft und Forschung), Sparkling Science Wissenschaft ruft Schule. Schule ruft Wissenschaft. Projektübersicht der 6. Ausschreibung, 2017 [https://www.sparklingscience.at/de/projects/ueberblick.html]. 